\title{
A Review of Quality Management Systems in South African HIV-AIDS Programmes: A Pre-Requisite for Sustainable Health Delivery
}

\author{
Shayhana Ganesh, Renitha Rampersad, Nirmala Dorasamy \\ Durban University of Technology, South Africa \\ shayhanaganesh@gmail.com
}

\begin{abstract}
The global commitment to end HIV-AIDS is a bold one; requiring a multi-sectoral response strongly embedded within effective HIV-AIDS prevention efforts, patient advocacy and effective healthcare programme delivery. UNAIDS estimates that, of the 36.7 million individuals infected with HIV-AIDS globally, 19.1 million reside in South Africa (UNAIDS Gap report, 2016).In addition, approximately 2.1 million new HIV infections occurred in 2015 with almost 960000 of those occurring in South Africa signalling that the rates of infections are not dropping as expected (UNAIDS Gap report, 2016). Given the unrelenting nature of this disease burden, even greater efforts are now required to turn the tide on HIV-AIDS globally, but more so in South Africa. These efforts entail more effective HIV-AIDS service delivery with combination prevention modalities, access to HIV-AIDS treatment and care, harm reduction of HIV-AIDS stigma and discrimination together with HIV-AIDS education, awareness and advocacy. Enhancing HIV-AIDS service delivery requires strong commitment with implementation of quality management systems in programme service delivery resulting in sustainable, effective and well run HIV-AIDS programmes. Quality management systems in HIVAIDS programmes allow programmes to successfully meet their objectives thus allowing optimal patient care through effective and efficient means. To date there has been minimal implementation of quality systems in healthcare especially in South Africa. The use of health quality tools and systems in HIV-AIDS programmes locally and globally will allow for efficient and cost effective benefits for the optimal wellbeing of all those affected and infected by HIV-AIDS. This article reviews available data on the prevalence of quality management systems in HIV-AIDS healthcare and identifies gaps and smart practises towards recommendations for comprehensive global HIV-AIDS standards development.
\end{abstract}

Keywords: Quality management systems, HIV-AIDS, sustainability, combination prevention modalities, HIVAIDS stigma and discrimination

\section{Introduction}

The South African HIV-AIDS response has been a long fight embodying issues of denialism, social injustice, politics, mortality and morbidity until finally significant achievements have been made in fighting this disease. The fight against HIV-AIDS has been a multi sectoral response with collaborative efforts being put forth from the state, parastatal and private health sectors. Significant funding from international donors and funders has helped alleviate the burden of disease within South Africa. Circa 2004,exponential amounts of financial spending has been invested in the South African epidemic from the first world countries alike in the form of research efforts, medication funding and clinical support (Morrison and Summers, 2013:1).Today the country can boast having more than 3.5 million people on antiretroviral therapy, This is the largest ARV programme in the world. HIV-AIDS prevention efforts appear to be yielding results such as aggressive approaches to treatment, expansion of Pre exposure prophylaxis, male medical circumcision, and continued condom provision, however the determinants of HIV-AIDS still need to be addressed to assist individuals at risk of HIV-AIDS acquisition (Simelela and Venter, 2014: 249). The multi sector response to HIV-AIDS has varied from NGO to public to private sectors with different sectors modelling their own components of HIVAIDS care based on their sector needs. Quality management in healthcare is a novel new concept and has experienced various levels of uptake in varied HIV-AIDS sectors globally and locally. Components of HIV-AIDS quality management programmes have begun to be implemented in HIV-AIDS programmes as evidenced by development of HIV-AIDS monitoring and evaluation frameworks for the public, NGO and civil HIV-AIDS health sectors. While the South African private HIV-AIDS sector, has commenced implementation of HIV-AIDS quality management systems through modalities such as the ISO certification, locally relevant and sector appropriate monitoring and evaluation frameworks for HIV-AIDS for the private sector remain elusive. An ISO certification standard, although indicated for HIV-AIDS, given the global and local on-going disease 
prevalence, still remains at large. Data that follows reviews components of quality management systems in healthcare and explores benefits in HIV-AIDS health service delivery and culminates with deficiencies, inefficiencies and gaps of HIV-AIDS quality management systems with recommendations for improvement.

\section{Literature Review}

Quality Management systems in healthcare: In the last ten years, significant improvements have been made with the quality of healthcare locally and globally. "Despite these advances, problems with quality persist. The quality of care for patients with HIV-AIDS infection is of particular concern" (Office of Health Standards Compliance, 2015).The South African Department of Health is the custodian of health matters in South Africa, as part of its mandate; The National Department of Health developed the Office of Health Standards Compliance (OCHS) to ensure that all South African health facilities comply with stringent standards of providing quality health care. The OHSC has the mandate to ensure that all South African health facilities comply with local standards in order to provide free, safe and equitable healthcare for all South Africans.

"A quality management system is a set of policies, processes and procedures required for planning and execution in the core business area of an organization"(International Organisation of standards, 2016).The purpose of quality healthcare is to ensure enhanced health service delivery together with ensuring clinic patron satisfaction. Batalden and Davidoff (2014:78) devised three focal areas where they believe the attention should be highlighted one.These are:

- "Patient Focus: Effective quality management is focused on the needs of the patients because they are the ones who judge the effectiveness of treatments and the appropriateness of the service."

- "Leadership: Quality management in health care requires the close cooperation of people with diverse expertise. Service providers should agree on the shared goal of providing quality service, and this can come about only if supervisors assume a leadership role and motivate employees."

- "External Environment: The health care sector is highly regulated and relies on state-of-the-art diagnostic technologies"

Health agencies across the world have also taken on the challenges of establishing quality management systems in various healthcare departments. The mission of the United States Department of Health and Human Services (HHS) is (United States Department of Health and Human Services, 2010):

- "To reduces the risk of harm from health care services by using evidence-based research and technology to promote the delivery of the best possible care;"

- "To transform the practice of health care to achieve wider access to effective services and reduce unnecessary health care costs; “

- "To improve health care outcomes by encouraging providers, consumers, and patients to use evidencebased information to make informed treatment decisions"

Carolyn, Clancy and Donabedian (1980:16) define quality in healthcare as: "very simply as health care quality is getting the right care to the right patient at the right time - every time."Carolyn, Clancy and Donabedian (1980:16)maintains in the United States context," that as attention has shifted from documenting that health care organizations and clinicians have the right equipment and training to deliver excellent care (structure), to assessing whether that competence is reflected in day-to-day care (process and outcomes), it has become clear that performance is often less than ideal." More attention now needed in growing quality management programmes in healthcare and by building adequate resources to promote and implement this. In areas of established quality healthcare, efforts should now be aimed at accelerating improvement in patient satisfaction and customer excellence toward sharing best practises in overcoming challenges in trying to establish quality management systems both globally and locally. 


\section{Components of Quality management systems in healthcare}

Quality planning: Quality planning refers: "to a systematic process that translates quality policy into measurable objectives and requirements, and lays down a sequence of steps for realizing them within a specified timeframe "(Varkey, Peller and Resar 2007: 736). "Quality planning is the first step where requirements are identified, criteria are set, and important procedures are recognized as part of the quality plan" (Varkey, Peller and Resar 2007: 736).

A key objective of healthcare quality planning is to ensure a clinical quality management plan is developed in line with the healthcare organisational structures. The plan should align core health quality principles with daily practise. A key feature of quality planning is to ensure the safe and satisfactory healthcare environment for patients and healthcare workers to exist in (Life healthcare, 2016).The integral component of quality planning in the healthcare sector is to ensure optimal patient treatment outcomes. This can be achieved through healthcare forecasting, clinical staff development and clinical training and capacitation. Clinical quality planning should be tailor made for the healthcare programme and organisation concerned to ensure that the strategic goals and mission of the healthcare facility is met.

Quality planning in management of HIV-AIDS programmes is of paramount importance. It is an important strategy to improve systems and reduce variation in delivery of care and services so that patients receive the correct care at every visit. Quality planning has become a fundamental component of the HIV-AIDS service delivery systems globally with emphasis being driven on continual improvement of HIV-AIDS related service delivery.; However, its uptake in the South African healthcare sector has been minimal and slow. A key objective of this research study is to develop clear monitoring and evaluation processes that will enable systematic collection, and interpretation of data that will lead to quality planning and improvement in the HIV-AIDS healthcare sectors.

An important aspect of quality planning in healthcare is performance measures in a health care setting which are derived from day to day clinical practice guidelines."Performance management is a forward-looking process used to set goals and regularly check progress toward achieving those goals" (International organisation of Standards, 2015).Performance measurement is a process by which an organization monitors important aspects of its programs, systems, and processes. Ensuring adherence to clinical guidelines and standards of care can be achieved by:

- "Maximizing collaboration and coordination of service providers to enhance access"

- "Promoting partnerships of consumers and providers that are respectful and promote client self-determination"

- "Providing services that are culturally appropriate and focused on individual client need"

- "Maximizing the efficient use of resources to provide cost-effective services"

Another critical aspect of quality management systems is quality control and quality assurance.

Quality control and quality assurance: Quality control is: " a procedure or set of procedures intended to ensure that a manufactured product or performed service adheres to a defined set of quality criteria or meets the requirements of the client or customer"(Varkey, Peller and Resar, 2007: 736).Quality control is : " needed to review the quality of the product or service. Inspection and testing is necessary to identify problems and defects that need correction". The importance of establishing quality control in the South African private and public health care sectors was necessary to standardize the medical treatment protocols to compare its usefulness in everyday medical institutions (Board of Healthcare funders, 2015). Healthcare needs to be viewed as a process and strive to minimize outside sources of variability and maximize efficiency and effectiveness. Quality and safety are important factors shaping the future of the healthcare industry for hospitals and medical care providers. Quality control is integral to healthcare as metrics shape medical practices and processes in place at the facilities in which they practice. Quality control defines both success and failure for healthcare workers and health facilities who lead in the healthcare industry. Quality control is 
a key component of healthcare but more so in HIV-AIDS related programmes given the high burden of disease both globally and locally.

Quality Assurance is "defined as a procedure or set of procedures intended to ensure that a product or service under development meets specified requirements" (Varkey, Peller and Resar, 2007: 736). Quality assurance is usually assessed together with quality control. The assurance procedures ensure that the standard of testing performed in the healthcare arenas allow for strict regulatory and quality criteria to be met. Quality assurance is of particular importance in the HIV-AIDS arena. In the field of HIV-AIDS, ensuring the correct and timely HIV diagnosis is given paramount importance. If an incorrect test result is given to the patient, the connotations are many that may affect the bio-psycho-social functioning of the individuals. Essential quality assurance procedures within the HIV-AIDS realm of healthcare are urgently needed to ensure standardisation and healthcare compliance among HIV-AIDS programmes and organisations. Given the high HIV-AIDS incidence and prevalence in our South African settings, it is both crucial and a priority that correct and accurate HIV test results are provided to the correct person being tested to prevent misdiagnosis of HIV status and suboptimal testing in certain areas. The South African HIV Counselling and testing campaign launched in 2009, has documented over 18 million South Africans who have been HIV tested to date (PEPFAR 2016).Stringent $Q A / Q C$ procedures have been enhanced at all major testing centres as quality assurance and quality control implemented through a quality management system is essential for any HIV testing service, ranging from HIV testing conducted in laboratories and health facilities to community-based settings. Comprehensive training packages and hands on training should be provided to all staff handling HIV testing. The turbulence we have faced and continue to face in the management of HIV-AIDS serves as a reminder for the continued need for management to go to develop to a higher and more effective level of management to allow for appropriate and efficient means of curbing the spread of HIV-AIDS. Quality assurance in HIV-AIDS programmes is critical for developing standards of consistency for clinical management, for application of these standards across the programme and for assessing its effectiveness in achieving the programme goals and objectives.

Quality improvement: Quality improvement in healthcare is: " a combined and unceasing effort of healthcare professionals, patients and their families, researchers, planners and educators to make the changes that will lead to better patient outcomes ,better system performance and better professional development" (Batalden and Davidof, 2007:22). In 1993, Dr. William Edwards Deming, one of the world's greatest minds on quality improvement, provided strong recommendations on quality improvement processes to healthcare and is well known for his five principles that have made a difference in healthcare. Deming stated : "quality improvement is the science of process management, if you cannot measure it...You cannot improve it, managed care means managing the processes of care, not managing physicians and nurses, the right data in the right format at the right time in the right hands and engaging the "smart cogs" of healthcare"(Deming, 1943). Quality improvement is defined as: "systematic and continuous actions that lead to measurable improvement in health care services and the health status of targeted patient groups" (United States Department of Health and Human Services, 2010).

Quality improvement in healthcare often encompasses the following key components (United States Department of Health and Human Services, 2010):

- Systems that affect patient access-these include the availability of accessible services for all individuals accessing healthcare and should be for the disabled, the elderly and the frail aged populations.

- Care provision that is evidence-based-A wealth of data supports clinical discretion and decision making that is factual and based on relevant evidence.

- Patient safety is of paramount importance in the healthcare industry and clinical standards should adhere

- Support for patient engagement and advocacy is critically important to ensure that patients are exposed to accurate levels of care and quality of care.

- Coordination of health systems is required to ensure that patients are dealt with holistically and from a bio-psycho-social approach to best quality healthcare. 
- Patient-centred communication is a pivotal component of ensuring quality of healthcare to patients to ensure that they are empowered to critically analyse decisions and make necessary decisions regarding their health and wellness.

Quality management efforts entail more effective HIV-AIDS service delivery with combination prevention modalities, access to HIV-AIDS treatment and care, harm reduction of HIV-AIDS stigma and discrimination together with HIV-AIDS education, awareness and advocacy.

\section{Methodology}

A retrospective data review was undertaken to ascertain the prevalence of quality management systems in healthcare globally and specifically in the arena of HIV-AIDS. The aim of this review was to assess available data on the prevalence of quality management systems in HIV-AIDS healthcare and identify gaps and smart practices towards recommendations for comprehensive global HIV-AIDS standards development. Local and global state, private, parastatal and non-governmental HIV-AIDS programmes were analysed in terms of their clinical wellness and management protocols toward quality management systems

Benefits of quality management systems in HIV-AIDS health service delivery: The implementation of quality management systems in healthcare and more specifically in HIV-AIDS healthcare can benefit organisations in various manners. The organisation for International standards (ISO) recognises that quality management systems in HIV-AIDS care can standardise healthcare products and services to allow for consistent service delivery (ISO, 2016). Quality management systems allow HIV-AIDS programmes to discover best practices to drive operational efficiency. HIV-AIDS quality management systems add credibility and confidence for patients and also allow organisations to explore new business opportunities for additional funds and grants. Ensuring continuous improvement and quality assurance allows an organisation a competitive edge and allows for brand recognition (ISO, 2016).Patient satisfaction is also a key component of quality management allowing patients to be satisfied with the care they have received and allows them to return for continued care. The end of HIV-AIDS will require mechanisms capable of supporting HIV-AIDS programmes; one such mechanism is quality management systems.

Deficiencies and gaps: It is imperative to note that not all health sectors have taken the challenge to implement quality management systems consistently. Some reasons for this include, implementation cost, dedicated personnel, set up, maintenance and documentation (Deming, 1964). Establishing and implementing quality management systems allow organisations to control and measure in order to review and improve (ASA, 2016).To date selected private health companies have embarked on ISO accreditation of their facilities in a bid to improve service delivery. The same has not been echoed in the public sector. Components of quality management systems have been developed such as monitoring evaluation frameworks for HIV-AIDS programmes in the NGO, public and civil sector but a similar framework for the private sector remains hopeful.

\section{Discussion and Conclusion}

This article highlighted the components and benefits of implementation of quality management systems in HIV-AIDS programmes .It displayed the value the organisations may experience from implementation of these systems. Literature reviewed also revealed that although the benefits of quality management systems have been demonstrated, very few healthcare organisations have taken up the implementation process. Reasons for this need to be assessed and analysed in order to address limiting factors to allow healthcare organisations to create enabling environments to establish quality management systems .This creates an urgent health priority and an identified gap which needs to be addressed. It is also pertinent to take note that selected components of quality management systems e.g. monitoring and evaluation frameworks are not being consistently developed and utilised for the various healthcare sectors. An identified gap is the devolvement of a locally relevant and contextually appropriate HIV-AIDS monitoring and evaluation framework that may be used across all healthcare sectors. Quality management systems in HIV-AIDS programmes allow programmes to successfully meet their objectives thus allowing optimal patient care 
through effective and efficient means. To date there has been minimal uptake of implementation of quality management systems in healthcare especially in South Africa. A locally relevant and contextually appropriate quality management tool for HIV-AIDS programme management is urgently required to be developed for adaption for use in the South African private, public, parastatal and non-governmental organizations.

Recommendations: Education and awareness activities governing quality management systems in healthcare should be encouraged among healthcare workers. Quality management systems certification should become necessary accreditation for all healthcare facilities Quality management systems in healthcare should form core curriculum in undergraduate and post graduate healthcare studies .A quality management system regulatory body should be developed locally and globally providing clinical governance to health facilities guiding best practices

\section{References}

Batalden, P.B. \& Davidoff, F. (2007).What is quality improvement and how can it transform healthcare? Quality Safe Health Care, 16(2-3) doi:10.1136/qshc.2006.022046

Batalden, P.B. \& Davidoff, F. (2014). Factors influencing healthcare service quality. International Journal of Health Policy Management, 3(2), 77-89. Published online 2014 Jul 26. Doi: 10.15171/ijhpm.2014.65 PMCID: PMC4122083\

Board of Healthcare Funders of Southern Africa. (2015). Home page. Available from https://www.bhfglobal.com/ [Accessed 16 June 2015]

Carolyn, M., Clancy, M. \& Donabedian, A. (1980). The definition of quality and approaches to its assessment. Ann Arbor: Michigan Health Administration Press:

Council for Medical Schemes [CMS]. (2016) Home page. Available from: https://www.medicalschemes.com/ [Accessed 15 May 2016]

Creswell, J.W. (2009).Research Design - Qualitative, Quantitative and Mixed Methods Approaches. 3rd ed. California: Sage Publications. Available from: http://ncbaeryk.yolasite.com/resources/John\%20W.\%20Creswell-

Research\%20Design_\%20Qualitative,

$\% 20$ Quantitative, \%20and\%20Mixed\%20Methods\%20Approaches-SAGE\%20Publications, \%20Inc\%20(2009).pdf [Accessed 14 May 2016]

Deming, W. E. (1964) [1943]. Statistical Adjustment of Data. Dover. ISBN 0-486-64685-8. LCCN 64-24416.

Life healthcare. (2015). Home page. Available from: https://www.lifehealthcare.com/[Accessed 15 June 2015]

International Organisation of Standards (ISO). (2016).Home page. Available from: http://www.iso.org/iso/home./ (Accessed 14 May 2016)

Office of Health Standards Compliance (OHSC). (2016). Home page. Available from: http://www.ohsc.org.za/ (Accessed 14 May 2016)

Simelela, N. P. \& Venter, W. D. F. (2014). A brief history of South Africa's response to AIDS. South African Medical Journal, 104(3), 249-251, Jan. 2014. ISSN 2078-5135. Available at: <http://www.samj.org.za/index.php/samj/article/view/7700>. Date accessed: 05 Feb. 2017. doi:10.7196/SAMJ.770

South African National Department of Health (DoH). (2016). Home page. Available from: http://www.health.gov.za/ (Accessed 14 May 2016)

The United States President's Emergency Plan for AIDS Relief (PEPFAR). Ninth annual report to congress on PEPFAR. PEPFAR, Washington, DC; 2013http://www.pepfar.gov/press/c57496.htm. (Accessed Jan 22, 2015)

United Nations UNAIDS Gap report 2016: UNAIDS Geneva, Switzerland; 2011http://www.unaids.org/unaids_resources/gap report.pdf. (Accessed Aug 19, 2016).

Varkey, P., Peller, K. \& Resar, R. K. (2007). Basics of quality improvement in healthcare. Mayo Clin. Proc., $82,735-739$

WHO. (2013). Consolidated guidelines on the use of antiretroviral drugs for preventing and treating HIV Infection, 2013. 